\title{
Refinement of the Affordable Care Act
}

By Vivian Ho, Ph.D.

James A. Baker III Chair in Health Economics, Baker Institute for Public Policy, Rice University

Professor in the Department of Economics, Rice University

Professor in the Department of Medicine, Baylor College of Medicine

vho@rice.edu

Corresponding Author:

Vivian Ho, Ph.D.

Rice University

6100 Main Street- MS 40

Houston, TX 77005-1827

Phone: (713)348-2195

Fax: (713)348-5993

Short Running Title: Refinement of the ACA

Disclosure Statement: The author declares that she has no relevant or material financial interests that relate to the research described in this paper. 
Keywords: Healthcare reform, Health insurance. Insurance Marketplace, Health economics, Price transparency, Medicaid

\begin{abstract}
:
Regardless of what legislation the federal government adopts in the coming year to address health insurance coverage for non-elderly Americans, private insurance will likely play a major role. This paper begins by listing some of the major reasons critics dislike the Affordable Care Act, then discusses the validity of these concerns from an economics perspective. Criticisms of the ACA include the increased role of government in healthcare, the ACA's implicit income redistribution, and concern with high and rising insurance premiums. Suggestions for refining the ACA and its market-based insurance system are then offered, with the goals of lower insurance premiums, improving coverage rates, and/or addressing the concerns of ACA critics. Americans favor the increase in insurance coverage that has occurred under the ACA. In order to sustain this level of coverage, steps to lower Marketplace premiums through a variety of strategies affecting potential enrollees, insurers, and healthcare providers are offered.
\end{abstract}




\section{INTRODUCTION}

The Affordable Care Act was signed into law by President Barack Obama in 2010. The major insurance provisions of the law did not take effect until 2014. An online marketplace accessed through the website healthcare.gov was launched in 2014, which enabled qualified individuals to purchase health insurance from private insurers offering plans meeting federal criteria. Qualified individuals included self-employed persons, as well as people who could not obtain affordable insurance coverage through their employer.

Enrollment in Marketplace plans reached 12.2 million in January 2017. (1) The majority of these enrollees received a tax credit from the ACA that substantially lowered the premium they pay for coverage. These subsidies make some Marketplace insurance policies free to persons in households earning $100 \%$ of the federal poverty level $(\$ 24,600$ for a family of four in 2017). (2) The subsidies are available in a declining amount up to households earning $400 \%$ of the FPL. Many more adult Americans with lower incomes gained insurance coverage through the expansion of Medicaid in their state. This figure was estimated to reach 11.1 million in 2016. (3)

In March 2017, Republicans were unsuccessful in their attempt to repeal the ACA. As declared by Republican House Speaker Paul Ryan, “Obamacare is the law of the land...We're going to be living with Obamacare for the forseeable future.” (4) Even so, Republicans are continuing their efforts to repeal and replace the ACA. And even if the law is replaced by alternative health care legislation, that alternative likely will continue to be market-based, with the majority of individuals under age 65 still purchasing coverage from private insurers. Thus, it 
is helpful to review the underlying economics of the ACA and determine what components could be refined in order to increase the affordability of health insurance and health care.

Before we consider refinements to the market for individual-purchased health insurance, we first summarize the main reasons for dissatisfaction with Obamacare. These concerns must be kept in mind when crafting changes in the legislation. While some Americans would advocate for universal coverage of all residents at any cost, this viewpoint is not supported by the majority of the population, and would not survive the political process in Washington, DC. This article proposes refinements that have some possibility of legislative success given the political factions in Washington, DC.

\section{WHAT IS DISLIKED ABOUT THE ACA?}

\section{The government should not be involved in the health insurance market.}

Some voters argue that the government should not play a role in providing health insurance to citizens. People with this viewpoint insist that government is already too large in the U.S, and that free markets in health insurance will achieve optimal outcomes for the population.

Indeed, economics demonstrates that in many situations, competitive markets lead to maximum social efficiency (the welfare of consumers and producers combined). However, economists assert that government intervention can be justified in instances of market failure, if the costs of government intervention are lower than the benefits gained from government control. (5) Market failure can occur in health care when patients lack information on the quality or effectiveness of a recommended treatment, or when insurers are unable to obtain an accurate 
prediction of the expected medical costs for a consumer who is seeking to buy health insurance. Most people with experience in health care can provide examples of these two market failures, and many more are outlined in Nobel prize winner Kenneth Arrow’s 1963 paper on the economics of medical care. (6)

Perhaps the most significant market failure in the U.S. health insurance industry results from adverse selection. (7) At any given premium, insurance coverage is more valuable to customers who are sicker on average than those who are well. As those with chronic illnesses buy more coverage, insurers must raise premiums to cover their medical expenses. These higher premiums in turn discourage healthy customers from purchasing insurance.

The individual mandate to purchase insurance that is included in the ACA mitigates rising health insurance premiums resulting from adverse selection, by requiring all persons to purchase coverage, regardless of health status. Some critics of the ACA view the mandate as "unfair" to young, healthier people, who are being forced to subsidize the healthcare costs of sicker individuals. However, some of these people will suffer acute health care events in any given year, for which they will benefit from having health insurance. And many others will develop costly chronic illnesses as they age. Just as young workers pay into the Social Security program in return for income security and access to Medicare when they retire, it may be "fair" for younger workers to pay for higher average premiums early on, in return for paying premiums lower than their predicted risk of health expenditures when they are older.

When considering components of the ACA that address adverse selection and other forms of market failure, it is important to keep in mind that the health insurance subsidies that are part of the ACA cause other distortions in the economy, such as crowd-out of private insurance and disincentives to work, or hire workers. $(8,9)$ 
The existence of externalities is another major argument for government intervention. For example, failure of some parents to vaccinate their children against measles or pertussis increases the risk of these diseases spreading to children who were previously immunized, generating additional medical costs for vaccinated families. $(10,11)$

Inevitably, many low-risk uninsured persons suffer acute health care illnesses that require costly hospitalizations that they cannot afford to pay. These uncompensated health care costs represent a negative externality to taxpayers, because public dollars finance the majority of care for the uninsured. Total uncompensated care in the U.S. was estimated at \$35 billion in 2001, with $\$ 30.6$ billion paid from government sources. (12) This $\$ 35$ billion represents $\$ 54.6$ billion in 2013, the year before the ACA insurance provisions were implemented. Under a range of assumptions, another study suggests that 50 percent of uninsured U.S. residents can afford to buy insurance. (13) Thus, prior to the ACA, the uninsured who could afford to purchase coverage were transferring as much as $\$ 27.3$ billion of their health expenditures onto taxpayers and other private entities subsidizing uncompensated care. The size of this externality is another justification for the individual mandate to purchase health insurance included in the ACA. Other options could be offered for reducing this externality, although they don't appear to present in any current legislation being considered by Congress.

\section{Obamacare is income redistribution}

A widely cited economics study notes that Americans devote a significantly lower share of GDP to social spending relative to their European counterparts. This difference in allocation of resources occurs, because a higher proportion of Americans believe that income is determined more by effort than luck, relative to Europeans. (14) The authors conclude that Americans 
remain more averse to government intervention than Europeans, even though Americans overestimate the level of social mobility in their country.

Public opinion polls suggest that Americans are divided along party lines about the role that government should play in reducing inequality. An early 2014 national survey (15) found that $90 \%$ of Democrats say the government should do "a lot” or "some” to reduce the gap between the rich and everyone else. However, only half as many Republicans (45\%) feel that the government should do something about this disparity. Americans also disagree on the approaches that should be taken to reduce poverty. In the same survey, $75 \%$ of Democrats believe that the government should raise taxes on the wealthy and corporations to expand programs for the poor. In contrast, only $29 \%$ of Republicans agreed with this statement. Many Americans support the ACA's increases in taxes on high-income earners, health insurance companies, medical device makers, and drug companies to fund health insurance for the poor. But a significant portion of the population disagrees with this approach to addressing poverty.

\section{Obamacare health insurance premiums are too expensive}

Americans who have private insurance coverage are dissatisfied with their high premiums. As of 2015, 55.7 percent of the population (16) had employer-provided coverage, compared to 35.9 percent with Medicare or Medicaid. Since the year after the ACA was signed into law (2011), premiums for single coverage provided by employers rose 18.5 percent, reaching $\$ 6,435$ in 2016. (17) While this increase is large, it is lower than the 25.4 percent increase in single coverage premiums for the 5-year period preceding passage of the ACA. During this time period, the share of premiums paid by workers versus employers also rose from 16 percent to 18 percent. Thus, while workers are dissatisfied with ever-rising health insurance 
premiums, these increases began well before the passage of the ACA. And if anything, the premium increases have slowed somewhat since ACA was passed.

Unlike for employer-provided health insurance, there is no comprehensive data source that tracks premiums for individual-purchased health insurance in the years prior to the ACA. One report (18) claims that 2017 premiums for individual-purchased insurance are lower than they would have been if the ACA had not been enacted. However, middle-income earners buying individual insurance must pay the full cost of their coverage, without federal subsidies, or the assistance from employers that people with employer-provided insurance receive.

Monthly premiums_(19) for the second-lowest silver plan in the Marketplace (a common benchmark) for a 40-year-old nonsmoker in 2017 range from a low of \$229 in Louisville, KY and Cleveland, $\mathrm{OH}$ to highs of $\$ 904$ in Anchorage, AK and $\$ 572$ in Charlotte, NC. If this 40year old earns $\$ 50,000$, she does not qualify for a premium tax credits, and therefore must pay for the full premium out-of-pocket, which would amount to $\$ 6,864$ in Charlotte, or $13.7 \%$ of her annual income. Even for a more moderately priced monthly premium of \$258 in Los Angeles, CA, the annual cost of insurance would be $\$ 3,096$, or $6.2 \%$ of annual income.

Taking into account food, housing, transportation, and other expenses, a relatively healthy single person earning $\$ 50,000$ will find the cost of health insurance in the Marketplace unacceptable; particularly because these plans also require a significant deductible and copays. The ACA provides substantial assistance to Americans near the federal poverty level to purchase health insurance. But middle class Americans who lack employer-provided insurance are still facing extraordinarily high costs to buy coverage. Changes to the ACA must be considered to make insurance affordable to the middle class, but keeping in mind that critics of the ACA are opposed to increasing redistribution of resources by the government. 


\section{POSSIBLE REFINEMENTS TO THE ACA}

Given the existing structure of the ACA, following are eight recommendations for refining the ACA within the context of common criticisms of the law.

\section{Expand the pool of individuals allowed to purchase catastrophic coverage beyond age 30.}

Many healthy adults who use few if any health care services are choosing to pay the penalty for not purchasing coverage, rather than buy a Marketplace plan. A single self-employed nonsmoker earning $\$ 75,000$ a year would have faced a penalty of $\$ 1,875$ (2.5\% of income) for not buying health insurance in 2016. In Brooklyn, NY, a catastrophic plan (20) was available in 2016 for $\$ 175$, less than half the amount of the lowest priced silver plan. The annual cost of this catastrophic plan is therefore $\$ 2,100$, which isn’t much more than paying the penalty. Assuming premiums for a catastrophic plan for a 40-year old wouldn’t be too much higher than for a 30year old, then allowing such persons to buy a catastrophic plan helps in three ways. It makes insurance somewhat more affordable to middle income households who don’t qualify for subsidies, and it reduces the externalities associated with uninsured persons requiring uncompensated care when they suffer costly, acute health care illnesses. Drawing these healthy individuals into the Marketplace may also help to lower premiums overall in the Marketplace, assuming that most healthy persons over age 30 who already have insurance coverage would not switch to these lean plans as well. 
Incidentally, it is difficult to find listings of catastrophic premiums by city on the web. There may be a substantial number of persons under age 30 who are paying the penalty for not having insurance, who would purchase a catastrophic plan if they knew the option exists.

\section{Widen the Age band limit beyond a 3-to-1 ratio.}

The ACA specifies that insurers can charge their oldest customers premiums that are no more than three times those of younger customers. Persons aged 45 to 54 are overwhelmingly represented in insurance Marketplaces, because the 3-to-1 age rating limit requires younger persons to pay too high a premium to subsidize the care of older, sicker patients. Enticing younger persons to enroll will raise the average level of health of the insured pool, which potentially lowers everyone’s premiums. The lower premiums cannot be extended to individuals who can be covered under their parents’ insurance plan, because doing so would shift substantial private costs to the public sector.

\section{Eliminate the requirement to cover preventive care in all health insurance policies.}

The ACA requires insurers to provide in-network coverage for certain preventive services such as colonoscopy and mammography, without charging copays or deductibles. (21) Coverage of these services yields reduced mortality and improved quality of life. However, providing additional preventive services and treating newly identified cases of disease raises expenditures and therefore health insurance premiums for insured persons, while adding to taxpayer costs. The goal of increasing preventive care is noble, but the public policy priority should be providing insurance coverage that protects against catastrophic circumstances to as many individuals as possible. Uninsured expenses for catastrophic care lead to the greatest externalities for the 
country as a whole. Removing the requirement to cover preventive services will help to lower premiums, enabling more persons to buy coverage.

\section{Reform the risk adjustment formula currently used to reimburse insurers.}

Marketplace insurers are compensated for enrolling patients with more documented illnesses, in order to discourage cherrypicking of the healthiest customers. The Center for Medicare and Medicaid Services is applying concurrent risk adjustment to the claims of Marketplace insurance enrollees. In this approach, funds are transferred in a budget neutral manner from issuers who had lower-risk enrollees to issuers who had higher-risk enrollees as determined at the end of the coverage year. (22) Risk is determined based on the enrollee's demographic data and the diagnoses recorded in insurance claims over the course of the year.

Concurrent risk adjustment encourages insurers to fully document patient illnesses, but provides no incentive to control costs. Reinsurance is an alternative approach to compensating insurers for enrolling high-risk customers. Under reinsurance, the federal government makes an additional payment to the insurer of 50 percent of costs for any enrollee whose costs fall between $\$ 90,000$ and $\$ 250,000$ in 2016. (23) Under the ACA, concurrent risk adjustment continues in the Marketplace indefinitely, while reinsurance was only effective from 2014 to 2016.

Yet a recent study suggests that a Marketplace in which insurers were compensated only under a reinsurance program would yield equivalent compensation for enrolling high-risk individuals relative to risk adjustment, but it would contain higher incentives for cost control. (24) This finding is consistent with intuition. Under risk adjustment, insurers have an incentive to construct a comprehensive list of all enrollees with chronic conditions in their patient population, for which they will receive additional compensation from the federal government. In many cases, 
providing additional services that increase spending will yield an opportunity for the insurer to record a chronic condition that will improve reimbursement under risk adjustment.

In contrast, reinsurance provides no such reward for aggressive coding. Yet insurers are still protected from the financial losses introduced by very high-cost patients. The mechanisms for reimbursing insurers in the Marketplace must be carefully reconsidered, so that the federal government is not overpaying for the insurance it is providing for enrollees.

\section{Foster accountable care organizations (ACO) within state Marketplaces.}

Under the ACA, Medicare encourages groups of doctors, hospitals, and other providers to form accountable care organizations (ACOs) that agree to deliver coordinated, high quality care to a group of at least 5,000 Medicare beneficiaries who receive the plurality of their care from the ACO. (25) The ACO enrolls fee-for-service Medicare beneficiaries, but if the providers can meet specified quality standards and hold annual spending to a predetermined amount below historic trend, then Medicare shares some of the savings with the ACO.

In 2015, the Medicare ACO Shared Savings Program generated \$429 million in gross savings to Medicare based on the performance of close to 400 ACOs. Only 31 percent of ACOs achieved sufficient cost savings to earn a bonus in 2015. However, ACOs are able to improve their performance with experience. Of those ACOs that were formed in 2012, 54.5 percent earned shared savings, while only 21.3 percent of the ACOs formed in 2015 achieved this goal. Thus, the Medicare Shared Savings Program has the potential to generate substantial savings to Medicare in the long run.

Currently, there is no mechanism for healthcare providers to offer ACOs to individuals seeking Marketplace coverage. Private insurers are negotiating ACOs with healthcare provider 
organizations in the private sector and successfully achieving cost savings. (26, 27) CMS should open up the opportunity for healthcare providers to offer ACOs through the Marketplace. In principal healthcare providers could do so now, but the rules set by CMS for introducing a health insurance policy in the Marketplace are too cumbersome for healthcare organizations that lack expertise in underwriting and selling health insurance. Given that ACOs are offered through Medicare, CMS should develop an analogous set of rules that would allow ACOs to provide comprehensive care to the non-Medicare population in the Marketplace. Doing so could achieve substantial cost savings in the long run.

\section{Reduce the generosity of the ACA's Medicaid expansion using cost-effectiveness analysis.}

The 2016 Medicaid actuarial report estimates that 2015 spending per newly eligible adult under the Medicaid expansion is \$6,365. (28) In contrast, the Congressional Budget Office estimates that the federal government is spending $\$ 4,240$ per subsidized individual (29) with Marketplace insurance in 2016. Those with Marketplace coverage have higher incomes, so they are paying for a higher share of their healthcare expenditures out-of-pocket. Yet this differential between Medicaid and Marketplace spending is particularly unappealing to those who oppose the ACA, because of the income redistribution the law represents.

Medicare does not include cost as a criterion for coverage of health care treatments, and therefore state Medicaid programs generally follow this practice too. Healthcare interventions that are costly, but that yield substantial health benefits, should be supported. And yet \$158 billion to $\$ 226$ billion of healthcare spending in the U.S. was estimated to be wasteful overtreatment (care that provides no benefit to patients). (30) A more targeted study asked expert clinicians to identify services with little or no clinical benefit on average, which could be readily 
identified using Medicare claims data. The clinicians identified 26 services, such as prostate specific antigen testing for men aged 75 and over, and electroencephalogram for headaches when no epilepsy or convulsions were noted in current or prior claims. These services were estimated to cost Medicare $\$ 1.9$ billion, or $\$ 71$ per beneficiary in 2009. (31)

Editorials suggest that cost-effectiveness is excluded from federal coverage decisions, because some lawmakers are concerned that the criterion will lead to rationing of beneficial treatments. $(32,33)$ These limits have extended to the ACA. The legislation created the PatientCentered Outcomes Research Institute (PCORI), (34) which funds research that improves healthcare decision making for providers and patients. While PCORI funds and reports results of comparative effectiveness analyses (i.e., which treatments yield the most health benefits), the institute is forbidden from developing or using cost per quality-adjusted life year thresholds. (35)

Those individuals and organizations who are critical of cost-effectiveness analysis (36, 37) also appear to be opposed to the ACA because of its implicit income redistribution, and because the cost of the program is too expensive. While these parties may be opposed to applying cost-effectiveness analysis to all Americans, they may be open to requiring that Medicaid deny coverage of treatments that are designated as wasteful by expert clinicians. New drugs and treatments could also be banned from Medicaid reimbursement, unless there are studies demonstrating that their cost per quality-adjusted life year is below a threshold of $\$ 100,000$. These actions would lower Medicaid expenditures, and they should have little (if any) negative impact on enrollees' health. In fact, studying the effects of this program, if enacted, would provide an excellent opportunity to determine whether the criteria of cost-effectiveness could be introduced more broadly in the U.S. healthcare system; doing so might substantially lower healthcare spending, while maintaining the quality of healthcare. 


\section{Lift the employer mandate for providing coverage to firms with $100+$ workers instead of}

50.

The ACA mandate that all firms with 50 or more (38) full-time-equivalent workers must offer affordable health insurance to their workers became effective in 2016. Requirements for

firms with 100 or more FTE workers were implemented in 2015. The Kaiser Family Foundation Employer Health Benefits survey found that the percentage of workers in firms with 50 to 199 workers who were covered by their employer's health insurance rose from 54 percent to 57 percent (17) between 2015 and 2016. However, this change was not statistically significant, and could therefore be attributable to sampling error. Thus, there is little evidence that the employer mandate for smaller firms is effective in increasing insurance coverage.

Meanwhile, the reporting requirements that employers must satisfy under the law have been labeled as time consuming and burdensome. $(39,40)$ The requirements are particularly burdensome for smaller firms, who cannot rely on economies of scale to cover human resource departmental costs associated with the law. Therefore, lawmakers should consider removing the employer mandate for firms employing between 50 and 99 workers.

\section{Increase Price Transparency}

With the increasing presence of high deductible insurance plans in both the employerprovided and individual-purchased markets, patients need access to price information from the range of providers offering diagnostic tests and procedures in their area. A variety of health care price shopping tools have become available, and all major insurers offer some sort of online price information for providers in their network. 
However, these price transparency tools vary in their comprehensiveness and ease of use. Perhaps because of these difficulties, a recent study found that few patients with high deductibles who received a range of costly outpatient services used a price searching tool developed by Aetna. (41) In particular, older and sicker patients were less likely to use the pricing tool.

Insurers may need to be more proactive in encouraging patients to use price transparency tools. For example, in one study, a benefits management firm found that patients who were preauthorized for a magnetic resonance imaging scan and who were sent information on price differences among available MRI facilities spent \$220 less per test than patients who were not contacted. (42) Another recent study found that workers who were given access to a particularly well-constructed pricing tool lowered the price of their health care services by $1.6 \%$. (43)

Insurance companies should have an incentive to disseminate price transparency tools if they lower the costs of medical services. However, existing studies are limited to evidence from one company or organization at a time, because studies with larger samples are costly and time consuming. The government can promote price transparency by funding larger, more comprehensive studies and disseminating best practices to insurers and benefits managers.

\section{CONCLUSION}

The main reason that the Affordable Care Act has become so contentious, is that healthcare has become extraordinarily expensive. Healthcare spending reached \$3.2 trillion (44) in 2015, or 17.8 percent of the nation's gross domestic product. The ACA contributes to that amount, because people with health insurance coverage spend more on medical care than those who are uninsured. Yet public opinion polls and media reports suggest that the majority of 
Americans favor the increase in insurance coverage that has occurred under the ACA. In order to sustain this level of coverage, it is imperative that steps be taken to lower Marketplace premiums through a variety of strategies affecting potential enrollees, insurers, and healthcare providers. Only by controlling growth in both insurance premiums and medical costs can hope to attain truly affordable care for Americans. 


\section{REFERENCES}

1. Centers for Medicare and Medicaid Services. 2017. Health Insurance Marketplaces 2017 Open Enrollment Period Final Enrollment Report: November 1, 2016 - January 1, 2017. CMS.gov. https://www.cms.gov/Newsroom/MediaReleaseDatabase/Fact-sheets/2017Fact-Sheet-items/2017-03-15.html

2. Office of the Assistant Secretary for Planning and Evaluation. U.S. Federal Poverty Guidelines Used to Determine Financial Eligibility for Certain Federal Programs. Poverty Guidelines. https://aspe.hhs.gov/poverty-guidelines

3. The Henry J. Kaiser Family Foundation. 2016. Medicaid Expansion Enrollment. Coverage under the Medicaid Expansion. http://kff.org/health-reform/state-indicator/medicaidexpansionenrollment/?currentTimeframe=0\&sortModel=\%7B\%22colId\%22:\%22Location\%22,\%22 sort\%22:\%22asc\%22\%7D

4. Lee M. 2017. What's Next for Paul Ryan? CNN. http://www.cnn.com/2017/03/24/politics/paul-ryan-health-care/

5. Pindyck RS, Rubinfeld DL. 1997. The analysis of competitive markets. In Microeconomics, pp. 289-329. Upper Saddle River, NJ: Prentice-Hall, Inc. 4th ed.

6. Arrow KJ. 1963. Uncertainty and the welfare economics of medical care. Am. Econ. Rev. 53(5):941-73

7. Akerlof GA. 1970. The Market for "Lemons”: Quality Uncertainty and the Market Mechanism. Q. J. Econ. 84(3):488

8. Sommers BD, Kenney GM, Epstein AM. 2014. New evidence on the Affordable Care 
Act: coverage impacts of early medicaid expansions. Health Aff. (Millwood). 33(1):78-87

9. Mulligan CB. 2015. Side effects and complications: The economic consequences of health-care reform. Chicago, IL: The University of Chicago Press Books

10. Gruber J. 2005. Why study public finance? In Public Finance and Public Policy, pp. 122. New York, NY: Worth Publishers

11. Phadke VK, Bednarczyk RA, Salmon DA, et al. 2016. Association Between Vaccine Refusal and Vaccine-Preventable Diseases in the United States. J. Am. Med. Assoc. 315(11):1149-58

12. Hadley J, Holahan J. 2003. How much medical care do the uninsured use, and who pays for it? Health Aff. Suppl Web(0278-2715 (Print)):W3-81

13. Bundorf MK, Pauly M V. 2006. Is health insurance affordable for the uninsured? $J$. Health Econ. 25(0167-6296):650-73

14. Alesina A, Angeletos G-M. 2004. Fairness and Redistribution. Am. Econ. Rev. 95(4):96080

15. Pew Research Center. Most See Inequality Growing, but Partisans Differ over Solutions. U.S. Politics \& Policy. http://www.people-press.org/2014/01/23/most-see-inequalitygrowing-but-partisans-differ-over-solutions/

16. Barnett JC, Vornovitsky M. 2016. Health Insurance Coverage in the United States, 2015. United States Census Bureau. https://www.census.gov/library/publications/2016/demo/p60-257.html

17. The Henry J. Kaiser Family Foundation, Health Research \& Educational Trust. 2016. 2016 Employer Health Benefits Survey. 2016 Annual Survey. http://kff.org/healthcosts/report/2016-employer-health-benefits-survey/ 
18. Adler L, Ginsburg PB. 2016. Obamacare premiums are lower than you think. Health Affairs. http://healthaffairs.org/blog/2016/07/21/obamacare-premiums-are-lower-thanyou-think/

19. Cox C, Long M, Semanskee A, et al. 2016. 2017 Premium Changes and Insurer Participation in the Affordable Care Act's Health Insurance Marketplaces. The Henry J. Kaiser Family Foundation. http://kff.org/health-reform/issue-brief/2017-premiumchanges-and-insurer-participation-in-the-affordable-care-acts-health-insurancemarketplaces/

20. Brandeisky K. 2016. 7 Dos and Don'ts for Freelancers Buying Health Insurance. Money. http://time.com/money/4251595/best-healthcare-for-freelancers/

21. Fox JB, Shaw FE. 2015. Clinical preventive services coverage and the Affordable Care Act. Am. J. Public Health. 105(1):e7-10

22. Centers for Medicare and Medicaid Services, Oversight C for CI and I. 2016. March 31, 2016, HHS-Operated Risk Adjustment Methodology Meeting

23. Cox C, Semanskee A, Claxton G, et al. 2016. Explaining Health Care Reform: Risk Adjustment, Reinsurance, and Risk Corridors. The Henry J. Kaiser Family Foundation. http://kff.org/health-reform/issue-brief/explaining-health-care-reform-risk-adjustmentreinsurance-and-risk-corridors/

24. Geruso M, McGuire TG. 2016. Tradeoffs in the design of health plan payment systems: Fit, power and balance. J. Health Econ. 47:1-19

25. Centers for Medicare and Medicaid, Services. 2015. Shared Savings and Losses and Assignment Methodology Specifications. Baltimore, MD

26. Song Z, Rose S, Safran DG, et al. 2014. Changes in Health Care Spending and Quality 4 
Years into Global Payment — NEJM. N. Engl. J. Med. 371(18):1704-14

27. Ho V, Allen TK, Kim U, et al. 2016. Measuring the Cost Implications of the Collaborative Accountable Care Initiative in Texas. Am. J. Manag. Care. 22(9):304-10

28. Actuary O of the. 2016. 2016 Actuarial Report on the Financial Outlook for Medicaid

29. Jost T. 2016. In Annual Baseline Budget Projections, CBO Decreases Marketplace Enrollment Estimates (Update). Health Affairs. http:/healthaffairs.org/blog/2016/03/25/in-annual-baseline-budget-projections-cbodecreases-marketplace-enrollment-estimates/

30. Berwick DM, Hackbarth AD. 2012. Eliminating Waste in US Health Care. J. Am. Med. Assoc. 307(14):1513-16

31. Schwartz AL, Landon BE, Elshaug AG, et al. 2014. Measuring Low-Value Care in Medicare. JAMA Intern. Med. 2115:1-9

32. Neumann PJ, Rosen AB, Weinstein MC. 2005. Medicare and Cost-Effectiveness Analysis. N. Engl. J. Med. 353(14):1516-22

33. Gold MR, Sofaer S, Siegelberg T. 2007. Medicare and cost-effectiveness analysis: Time to ask the taxpayers. Health Aff. 26(5):1399-1406

34. Patient Centered Outcomes Research Institute. http://www.pcori.org/about-us

35. Neumann PJ, Weinstein MC. 2010. Legislating against Use of Cost-Effectiveness Information. N. Engl. J. Med. 363(16):1495-97

36. Avorn J. 2009. Debate about funding comparative-effectiveness research. $N$ Engl J Med. 360(19):1927-29

37. Iglehart JK. 2010. The Political Fight Over Comparative Effectiveness Research. Health Aff. 29(10):1757-60 
38. Obamacare Employer Mandate. Obamacare Facts.

https://obamacarefacts.com/obamacare-employer-mandate/

39. Politico. 2013. How Obamacare affects businesses

40. Watts T. 2014. ACA Top Concern : Handling the Administrative Burden. Mercer Signal. http://ushealthnews.mercer.com/article/169/aca-top-concern-handling-the-administrativeburden

41. Sinaiko AD, Rosenthal MB. 2016. Examining a health care price transparency tool: Who uses it, and how they shop for care. Health Aff. 35(4):662-70

42. Wu S jung, Sylwestrzak G, Shah C, et al. 2014. Price transparency for MRIs increased use of less costly providers and triggered provider competition. Health Aff. 33(8):1391-98

43. Ethan Lieber BM, Evans B, Gentzkow M, et al. 2017. Does It Pay to Know Prices in Health Care? Am. Econ. J. Econ. Policy. 9(1):154-79

44. Centers for Medicare \& Medicaid Services. National Health Expenditure Data. CMS.gov. https://www.cms.gov/research-statistics-data-and-systems/statistics-trends-andreports/nationalhealthexpenddata/nationalhealthaccountshistorical.html 